Imaging and Characterizing the Waste Materials Inside an Underground Storage Tank Using Seismic Normal Modes

Final Report - 09/15/1996 - 09/14/1999

M. N. Toksoz

R. M. Turpening

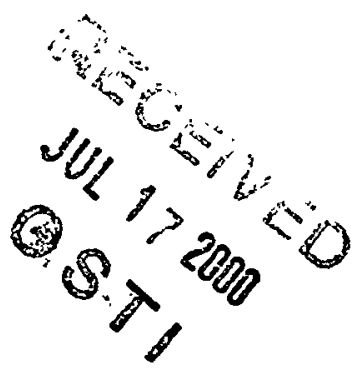

September 1999

Work Performed Under Contract No. DE-FG07-96ER14705

For

U.S. Department of Energy

Assistant Secretary for

Energy Research

Washington, DC

By

Massachusetts Institute of Technology

Cambridge, MA 


\section{DISCLAIMER}

This report was prepared as an account of work sponsored by an agency of the United States Government. Neither the United States Government nor any agency thereof, nor any of their employees, make any warranty, express or implied, or assumes any legal liability or responsibility for the accuracy, completeness, or usefulness of any information, apparatus, product, or process disclosed, or represents that its use would not infringe privately owned rights. Reference herein to any specific commercial product, process, or service by trade name, trademark, manufacturer, or otherwise does not necessarily constitute or imply its endorsement, recommendation, or favoring by the United States Government or any agency thereof. The views and opinions of authors expressed herein do not necessarily state or reflect those of the United States Government or any agency thereof. 


\section{DISCLAIMER}

Portions of this document may be illegible in electronic image products. Images are produced from the best available original document. 


\section{IMAGING AND CHARACTERIZING THE WASTE MATERIALS INSIDE AN UNDERGROUND STORAGE TANK USING SEISMIC NORMAL MODES}

FINAL REPORT - 09/15/1996 - 09/14/1999

M. N. Toksov

R. M. Turpening

September 1999

Work Performed Under Contract No. DE-FG07-96ER 14705

Prepared for the

U.S. Department of Energy

Assistant Secretary for

Energy Research

Washington, DC

Prepared by

Massachusetts Institute of Technology

Cambridge, MA 


\title{
IMAGING AND CHARACTERIZING THE WASTE MATERIALS INSIDE AN UNDERGROUND STORAGE TANK USING SEISMIC NORMAL MODES
}

\author{
FINAL REPORT FOR PERIOD \\ SEPTEMBER 15, 1996-SEPTEMBER 14, 1999
}

\author{
M. Nafi Toksöz and Roger M. Turpening \\ Earth Resources Laboratory \\ Department of Earth, Atmospheric, and Planetary Sciences \\ Massachusetts Institute of Technology \\ Cambridge, Massachusetts 02139
}

Prepared for

THE U.S. DEPARTMENT OF ENERGY

AGREEMENT NO. DE-FG07-96ER14705

NOTICE: This report was prepared as an account of work sponsored by the United States Government. Neither the United States nor the Department of Energy, nor any of their employees, nor any of their contractors, subcontractors, or their employees, makes any warranty, express or implied, or assumes any legal liability or responsibility for the accuracy, completeness, or usefulness of any information, apparatus, product or process disclosed or represents that its use would not infringe privately-owned rights. 


\section{TABLE OF CONTENTS}

Executive Summary 3

Research Objectives 5

Methods and Results 5

Seismic Characterization of Nuclear Waste Storage Tanks 5

1. Summary 5

2. Introduction 6

3. Theoretical Approach to Free Vibrations of a Tank Partially Filled With a Homogeneous Fluid $\quad 7$

4. Theoretical Approach to a Tank Partially Filled With Layers of Fluids 11

5. Numerical and Laboratory Results 15

6. Conclusions 31

Relevance, Impact and Technology Transfer 35

Project Productivity 36

Personnel Supported 36

$\begin{array}{ll}\text { Publications } & 36\end{array}$

$\begin{array}{ll}\text { Interactions } & 36\end{array}$

Transitions $\quad 36$

$\begin{array}{ll}\text { Patents } & 37\end{array}$

$\begin{array}{ll}\text { Future Work } & 37\end{array}$

$\begin{array}{ll}\text { Literature Cited } & 37\end{array}$

$\begin{array}{ll}\text { Appendix } & 38\end{array}$ 


\section{EXECUTIVE SUMMARY}

Observing and sampling the contents of Hanford's underground storage tanks has always been a difficult problem. Although various types of coring and sampling devices exist, one sampling operation is time-consuming, difficult, and even at its best results in only a point measurement of a large volume. Furthermore, at various times in the past it has been especially important to know whether an entire gas layer or volume existed in the waste of a given tank.

Many techniques exist in the hydrocarbon industry for imaging the earth, but it is not easy to employ them in a tank. The best imaging methods require two boreholes in a tank, and indeed the MIT Earth Resources Laboratory (ERL) was successful in implementing such a method in tank 114 TX using its two liquid observation wells (LOWs). However, all other tanks have only one LOW, which controlled the direction of the work reported here.

Given the importance of knowing as much as possible about the contents of a specific tank and given that the tank will have only one LOW, we examined the information that could be obtained from the natural seismic vibrations of a tank as a whole, that is, the normal modes of that tank. As in the case of a bell, the natural vibration, or normal modes, of a tank depend on many things, including the construction of the tank, the kinds of waste materials in the tank, the amount of each material in the tank, and where the energy is placed that excites the vibrations (i.e., where you will "hit" the tank).

The nature of natural vibrations is not affected by where one "listens" to them, although one might miss one or several "overtones" if the recording instruments are in poor locations. Throughout this research it was assumed that the "listening devices" would be hydrophones and they would be deployed in the one LOW that exists in every tank. It was also assumed that in any future deployment of this method, the seismic energy to excite the natural vibrations would be a small vibrator placed outside a tank and on the earth's 
surface. The research reported here involves the theoretical computations and small physical model studies needed to understand these normal modes.

We used layered models, both numerically and physically, of wastes in a tank. These restrictions in no way reduced the value of the research. We were seeking a measure of the sensitivity of the normal modes to the kinds and volumes of wastes in a tank.

The nature of a normal mode of vibration can be given by its frequency and amplitude. For any given frequency, the amplitude of vibration can be given as a function of position in and around the tank. Since we assumed that one would be "listening" to a tank from locations along a LOW, we show our computed amplitudes as a function of position inside and around the tank, and in the case of our physical models we display the observations along various lines inside the tank model. This allowed us to see the complex geometry of each mode of oscillation as a function of increasing frequency.

Several different liquids (oil, water, heavy mud, etc.) were used both numerically and physically. We observed strong differences in location of the spectral peaks for layers (of various thicknesses) of liquids that differed only slightly in density. We also changed the total volume of wastes in a given tank.

We scaled our results up to represent full-sized Hanford tanks and found that the spectral band of the normal modes was in a range of frequency (tens to hundreds of Hertz) that is easy to generate and record in the field. Thus a technique that, with a minimum of intrusion, can discriminate various total volumes of layered wastes, stands ready for field testing should that be desired.

This research was presented as one of the general examination papers required of a Ph.D. graduate student in the Department of Earth, Atmospheric, and Planetary Sciences at MIT. 


\section{RESEARCH OBJECTIVES}

It is necessary to know something about the nature of the wastes in a Hanford underground storage tank (UST) so that the correct hardware can be inserted into a tank for sampling, sluicing, or pumping operations. It is also important to know if a layer of gas exists beneath solid and liquid layers of waste. Each tank has one liquid observation well (LOW) that can be used for instrumentation.

The objective of this research was to determine the usefulness of normal mode theory in determining the amount and nature of wastes in Hanford's underground storage tanks (USTs). All objects, such as a bell or the spherical earth, "ring" at a set of natural frequencies when excited by hitting (in the case of a bell) or an earthquake (in the case of the earth as a whole). The frequency where the "ringing" occurs and the amplitude of that "ring" is determined in part by the properties of the bell or the earth.

This project was undertaken to determine the sensitivity of the frequency and its amplitude to the volume of waste in a tank and its (layered) nature. We assumed that one would "listen" to the ringing of a tank with receivers placed in the one available LOW.

\section{METHODS AND RESULTS}

\section{SEISMIC CHARACTERIZATION OF NUCLEAR WASTE STORAGE TANKS}

\section{Summary}

Free vibrations of a cylindrical tank of finite size partially filled with layers of inviscid and compressible liquids, are analytically studied. As a body of finite size, the tank can resonate as a whole to seismic sources only at certain discrete frequencies. The resonance spectrum characterizes the physical properties of the tank-fluids system, such as velocities and mass densities of fluids. Each resonance frequency corresponds to a specific mode of vibration that distributes spatially and is represented by one of a group of orthogonal eigenfunctions. This work is directed toward finding a way to estimate the 
physical properties of the waste in tanks at the Hanford Reservation with minimal use of instrumentation in the tanks. Preliminary laboratory ultrasonic scale model experiments show agreement with analytical calculations in both frequency and spatial distribution.

\section{Introduction}

The storage of hazardous wastes in underground tanks is a common practice. An extreme example can be found at the Hanford Facility in Washington State, where 177 cylindrical steel tanks store high-level radioactive and toxic wastes since Hanford's weapons production activities. Each tank is about $23 \mathrm{~m}$ in diameter and $13 \mathrm{~m}$ high, covered with a thick concrete shell and contains between several thousand to over one million gallons of waste. Because some of the tanks are leaking and contaminating the subsurface environment, the Department of Energy is developing remediation plans.

The wastes are likely to be a mixture of liquid and solid phases, and most likely they are stratified in layers. The characterization of the physical state of the wastes will provide vital information for planning and operational support to the transfer and remediation of the contents of the tanks. It is equally important that any survey of the contents of the tanks be done in a cost-effective and timely manner.

Initial on-site seismic measurements inside the tanks show strong harmonic modes or standing waves as opposed to transient ones (Turpening et al., 1995). In this report, we propose a seismic method using harmonics, as has been used for the earth's free oscillations, to assess the physical properties of the wastes (Gilbert and Dziewonski, 1975; Mochizuki, 1986; Migliori et al., 1993). As the initial step of the investigation, wastes inside the tanks are considered as inviscid and compressible layered fluids. A theoretical approach to characterize harmonic vibrations of a cylindrical tank partially filled with layers of fluids is developed by solving a boundary-value problem. Based on the theory, it is found that harmonics of a tank-fluids system are simple functions of both tank geometries and physical properties (densities, moduli) of the fluids; therefore, measuring harmonics of the tank-wastes system is a simple way to characterize the physical status of the wastes. In 
order to examine our theory, ultrasonic scale model experiments were carried out in the laboratory. Laboratory results and theoretical computations exhibited close matches in both harmonic or resonance frequencies and spatial distributions of harmonic vibrations.

\section{Theoretical Approach to Free Vibrations of a Tank Partially Filled With an Homogeneous Fluid}

The cylindrical storage tanks are made of steel and sealed by a thick concrete shell. Before we investigate free vibrations of a tank partially filled with multiple fluids, it is worthwhile to study free vibrations of a tank partially filled with a single fluid. Figure 1 shows a diagram of the tank-fluid system and coordinates that are used here. The following Helmholtz equation describes small-amplitude wave propagating in inviscid and compressible fluid,

$$
\nabla^{2} \Phi=\frac{1}{\mathcal{V}_{f}^{2}} \ddot{\Phi}
$$

where $\Phi$ and $v_{f}$ denote the compressional displacement potential and fluid compressional velocity, respectively. Applying separation of variables and the natural boundary condition for the circumferential direction: $e^{i \theta}=e^{i(\theta+2 \pi)}$, we obtain the general solution to the above Helmholtz equation in cylindrical coordinates (Butkov, 1968),

$$
\Phi(t, r, \theta, z)=J_{n}\left(k_{r} r\right) e^{i n \theta}\left[A \cos \left(k_{z} z\right)+B \sin \left(k_{z} z\right)\right] e^{i \omega t}
$$

where $J_{n}\left(k_{r} r\right)$ is the Bessel function of the $n$th order, characterizing vibration distributions in the radial direction. Wavenumbers in the radial and axial direction, $k_{r}$ and $k_{z}$, are to be determined by boundary conditions in radial and axial directions, respectively. Note that the radial and circumferential directions are coupled to each other through eigenvalues in the $\theta$ direction, $n$. 


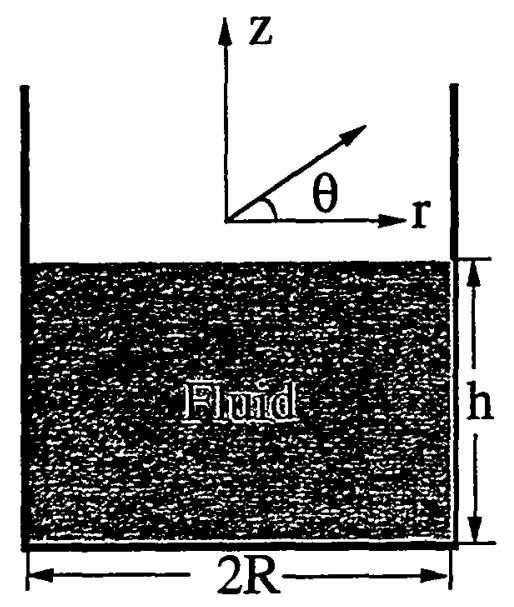

Figure 1: Diagram of a tank partially filled with a homogeneous fluid and the corresponding coordinates. 
As the steel tank is covered with a thick concrete shell and buried underground, the tank wall is considered a rigid boundary; therefore, radial displacement $u_{r}$ at $r=R$ and axial displacement $u_{-:}$at $z=0$ vanish:

$\left.U_{r}\right|_{r=R}=0$

and

$\left.u_{z}\right|_{z=0}=0$

where $u_{r}=\frac{\partial \Phi}{\partial r}$ and $u_{z}=\frac{\partial \Phi}{\partial z}$,

representing displacements in the radial and axial directions, respectively. $R$ denotes the tank radius. At the fluid surface $z=h$, we apply the free surface boundary condition:

$\left.P\right|_{:=h}=0$

where $P=\rho_{f} \omega^{2} \Phi$, representing the fluid pressure field that is caused by small amplitude waves, $\rho_{f}$ is fluid mass density and $\omega$ denotes the angular frequency. Applying the boundary conditions [equations (3), (4), and (5)] to the general solution [equation (2)] of the Helmholtz equation, we obtain eigenvalues for the radial and axial directions.

$k_{z l}=\frac{\pi}{h}\left(\frac{1}{2}+l\right), \quad$ with $l=0,1,2, \cdots$

and

$k_{r m}^{(n)}=\frac{\operatorname{root}\left[J_{n}^{\prime}(x)\right]}{R}, \quad$ with $m=1,2, \cdots$

where $J^{\prime}$ denotes the derivative of $J_{n}$ with respect to the argument, $x$.

Thus, $k_{r m}^{(n)}, k_{z l}$, and $n$ represent a complete set of eigenvalues that characterize free vibrations of the tank-fluid system. The displacement potential that thoroughly describes the corresponding wavefield, therefore, should be linear combinations of all the eigenfunctions, 
$\Phi(t, r, \theta, z)=\sum_{m} \sum_{n} \sum_{l} A_{m, n, l} J_{n}\left(k_{m}^{n} r\right) e^{i n \theta} \cos \left(k_{z l} z\right) e^{i \omega t}$.

Note that the term $\sin \left(k_{z} z\right)$ drops out in order to fit the rigid boundary condition at $z=0$.

Each of the eigenfunctions $J_{n}\left(k_{r m}^{(n)} r\right) e^{i n \theta} \cos \left(k_{z l} z\right) e^{i \omega t}$

represents a harmonic vibration mode that contributes a peak in the resonance spectrum.

Substituting equation (8) into the Helmholtz equation (1), we obtain an expression that calculates harmonic or resonance frequencies:

$$
f_{m . n . l}=\frac{v_{f}}{2 \pi} \sqrt{k_{z l}^{2}+\left(k_{r m}^{(n)}\right)^{2}}
$$

Note that $f_{m, n, l}$ is a set of discrete frequencies. The lowest frequency, the cut-off frequency of the resonance spectrum, of the aforementioned tank-fluid system corresponds to mode $(1,0,0)(m=1, n=0, l=0)$. Mode $(m, n, l)$ indicates that the pressure field has $m, n, l+1$ anti-nodes in the radial, circumferential and axial directions, respectively. The cut-off frequency is then given by

$$
f_{r}=\frac{v_{f}}{4 h}
$$

which is only related to the fluid velocity and the height of the fluid. Equation (10) is useful for designing the frequency range of on-site measurements. The velocity and height of the fluid can be calculated using two harmonic modes by using equation (9).

When the source is on the $z$-axis, it is at the common node of vibration modes with the circumferential eigenvalue $n$ bigger than 0 , as $J_{n}(0)=0$ for $n>0$; thus, harmonics with $n>0$ cannot be excited. Vibration modes that can be excited are those with the circumferential eigenvalue equal to zero; therefore, equation (7) becomes

$k_{r m}^{(0)}=\frac{\operatorname{root}\left[J_{1}(x)\right]}{R}, \quad$ with $m=1,2, \cdots$ 
Note that $J_{0}^{\prime}(x)=J_{1}(x)$. For simplicity, when $n=0$, a harmonic vibration of mode $(m, n$, $l)$ is referred to as mode $(m, l)$.

\section{Theoretical Approach to a Tank Partially Filled With Layers of Fluids}

When the tank contains layers of fluids, corresponding harmonic vibrations are much more complicated than those in a single-layered tank as vibrations are different in each layer due to different layer thicknesses and fluid properties. Figure 2 shows the geometry of a tank partially filled with $N$ layers of fluids. The thickness of the $j$-th layer is $h_{j}-h_{j-1}$. In each layer, the Helmholtz equation still holds; therefore, in the $j$-th layer,

$$
\nabla^{2} \Phi_{j}=\frac{1}{v_{i}^{2}} \ddot{\Phi}_{j}, \quad \text { with } j=1,2, \cdots, N
$$

where $\Phi_{j}$ and $v_{j}$ denote the displacement potential and the fluid velocity of the $j$-th layer, respectively. Similarly, we obtain the general solutions to each of the Helmholtz equations in cylindrical coordinates by applying separation of variables and natural boundary conditions for the $\theta$ direction:

$$
\Phi_{j}=\sum_{m} \sum_{n} J_{n}\left(k_{m m}^{(n)} r\right) e^{i n \theta}\left[A_{m . n}^{(j)} \cos \left(k_{z}^{(j)} z\right)+B_{m . n}^{(j)} \sin \left(k_{z}^{(j)} z\right)\right]
$$

For each layer, eigenvalues in radial and $\theta$ directions remain the same as for the one layer case since boundary conditions for the radial and $\theta$ directions remain unchanged.

Substituting general solutions, equation (13), into Helmholtz equations, equation (12), we obtain an expression that relates frequencies with radial and axial wavenumbers at the $j$-th layer,

$$
f_{m, n}=\frac{v_{k}}{2 \pi} \sqrt{\left(k_{z}^{(j)}\right)^{2}+\left(k_{r m}^{(n)}\right)^{2}}, \quad \text { with } j=1,2, \cdots, N
$$




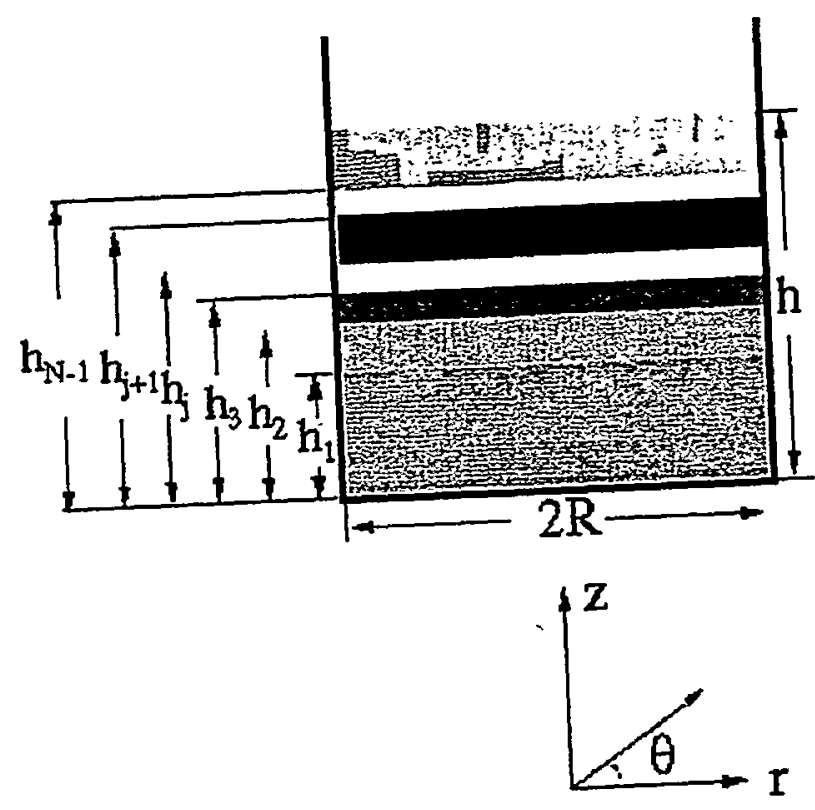

Figure 2: Diagram of a tank partially filled with $\mathrm{N}$ layers of fluids. 
Eigenvalues in the axial direction are to be determined by boundary conditions at each of the fluid boundaries for the axial direction: continuity of the displacement in the axial direction and the pressure field at each of the boundaries, which are expressed below:

$$
\begin{aligned}
& \left.u_{z}^{(1)}\right|_{z=0}=0 \\
& \left.u_{z}^{(1)}\right|_{z=h_{1}}=\left.u_{z}^{(2)}\right|_{z=h_{1}} \\
& P_{\mathrm{l}_{z=h_{1}}}=P_{\left.2\right|_{z=h_{1}}} \\
& \left.u_{z}^{(j)}\right|_{z=h_{j}}=\left.u_{z}^{(j+1)}\right|_{z=h_{j}} \\
& \left.P_{j}\right|_{z=h_{j}}=P_{j+\left.\right|_{z=h_{j}}} \\
& \left.u_{z}^{(N-1)}\right|_{z=h_{N-1}}=\left.u_{z}^{(N)}\right|_{z=u_{N-1}} \\
& \left.P_{N-1}\right|_{z=h_{N-1}}=\left.P_{N}\right|_{z=h_{N-1}} \\
& \left.P_{N}\right|_{z=h}=0
\end{aligned}
$$

where

$$
u_{z}^{(j)}=\frac{\partial \Phi_{i}}{\partial z}
$$

and

$$
P_{j}=\rho_{f}^{(j)} \omega^{2} \Phi_{j}
$$

$\rho_{f}^{(j)}$ denotes the fluid mass density in the $j$ - th layer.

Substituting equations (13), (16), and (17) into equation (15), a set of linear equations regarding to coefficients

$A_{m, n}^{k}$ and $B_{m, n}^{k}$ are obtained and expressed in a matrix form as 
$\mathrm{C} x=0$

where

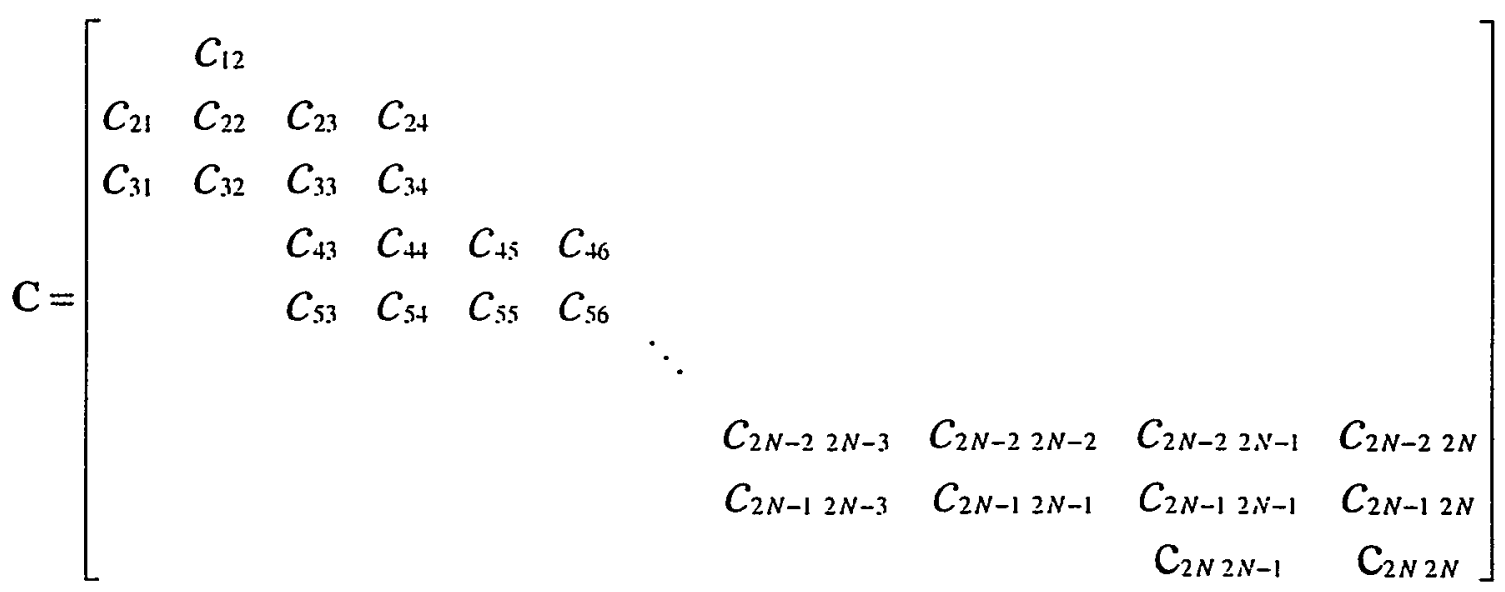

and

$A_{m . n}^{(1)}$

$B_{m, n}^{(1)}$

$A_{m, n}^{(2)}$

$B_{m, n}^{(2)}$

$A_{m, n}^{(3)}$

(20)

$B_{m, n}^{(3)}$

$\vdots$

$A_{m, n}^{(N)}$

$B_{m, n}^{(N)}$

Zeroes are absent in matrix $\mathrm{C}$. Non-zero elements in $\mathbf{C}$ are functions of axial wavenumbers, fluid densities and velocities (see the Appendix). As we are only interested in non-trivial solutions for all

$A_{m, n}^{(j)}$ and $B_{m, n}^{(j)}$ with $j=1,2, \cdots$, and $N$, the determinant of matrix $\mathbf{C}$ must be zero,

$f\left(k_{z}^{(j)}\right)=|\mathbf{C}|=0, \quad$ with $j=1,2, \cdots$, and $N$.

From the $N$ equations that relate frequencies with radial and axial wavenumbers, 
equation (14),

$k_{z}^{(2)}, k_{z}^{(3)}, \cdots$, and $k_{z}^{(N)}$ can be expressed in terms of $k_{z}^{(1)}$,

$$
\begin{aligned}
& k_{z}^{(2)}=\sqrt{\frac{v_{1}^{2}}{v_{2}^{2}}\left[\left(k_{z}^{(1)}\right)^{2}+\left(k_{r m}^{(n)}\right)^{2}\right]-\left(k_{r m}^{(n)}\right)^{2}}, \\
& k_{z}^{(3)}=\sqrt{\frac{v_{1}^{2}}{v_{3}^{2}}\left[\left(k_{z}^{(1)}\right)^{2}+\left(k_{r m}^{(n)}\right)^{2}\right]-\left(k_{r m}^{(n)}\right)^{2}}, \\
& \vdots \\
& k_{z}^{(N)}=\sqrt{\frac{v_{1}^{2}}{v_{N}^{2}}\left[\left(k_{z}^{(1)}\right)^{2}+\left(k_{r m}^{(n)}\right)^{2}\right]-\left(k_{r m}^{(n)}\right)^{2}} .
\end{aligned}
$$

Substituting equation (22) into equation (21), a function of $k_{z}^{(1)}$ is obtained,

$G\left(k_{z}^{(1)}\right)=0$

Thus, with equations (23) and (22), eigenvalues in the axial direction can be completely resolved. Resonance frequencies, functions of fluid velocity, mass density and thickness of each layer can then be calculated with equation (14). For $N$ layers of fluids, the number of resonance frequencies in the resonance spectrum that can resolve fluid velocity, mass density and thickness of each layer is $3 N$.

\section{Numerical and Laboratory Results}

As a check on the analytical solutions as well as feasibilities of using the resonance spectrum to resolve fluid properties in the tanks, we built a small physical model tank and conducted experiments in the laboratory. Two groups of experiments were carried out with respect to two different fluid contents: pure water or oil and water. We measured resonance spectrums and vibration distributions in both radial and axial directions for a number of harmonic vibrations. 
A steel pot is used as a scale tank model in the experiment. The source, $1.5 \mathrm{~cm}$ in diameter, is a spherical ultrasonic transducer with a broad band-width in frequency. The receiver is a hydrophone that has a flat response for frequencies below $100 \mathrm{kHz}$. Figure 3 indicates the dimensions of the model tank filled with oil and water and the location of the source and receivers in the model tank that measure the resonance spectrum of the system. In the case of pure water in the model tank, the height of the water is the same as the total height of the oil and water, $23 \mathrm{~cm}$.

First, we estimated the frequency range where several harmonics of the lowest frequencies can be observed in the experiment using equation (9), and chose the frequency range of $1 \mathrm{kHz}$ to $20 \mathrm{kHz}$ for our experiment. Velocities of water and oil are $1480 \mathrm{~m} / \mathrm{s}$ and $1380 \mathrm{~m} / \mathrm{s}$, respectively. The radius of the model tank is $15 \mathrm{~cm}$. The steel pot was not covered with a thick concrete shell and buried underground as Hanford tanks are; thus, it is necessary to evaluate whether the rigid boundary condition is appropriate for the steel pot as it is for the Hanford tanks. Wavelengths of the wavefield in the experiment are in the range of $7 \mathrm{~cm}$ to about $150 \mathrm{~cm}$ for frequencies of $1 \mathrm{kHz}$ to $20 \mathrm{kHz}$, much longer than the thickness of the pot wall (several milimeters); therefore, it makes no appreciable difference whether or not the pot wall exists. Thus, the pot wall in our experiment represents a free surface instead of a rigid wall. As the rigid boundary condition of the tank wall could not be simulated in the laboratory, we adjust our theory accordingly so as to fit the experiment. For free surface boundary conditions, equation (11) should be adjusted accordingly: $k_{r m}^{(0)}=\frac{\operatorname{root}\left[J_{0}\right](x)}{R}, \quad$ with $m=1,2, \cdots$

We choose $n=0$ because the source was put on the $z$-axis.

Resonance spectrums in Figures 4 and 5 were obtained while the source generated a continuous sinusoidal signal that was slowly moved up in frequency. Peaks in the measured resonance spectrums represent harmonic frequencies that are discrete for both the water and oil-water model tanks, as predicted by the theory. In order to identify each of the 


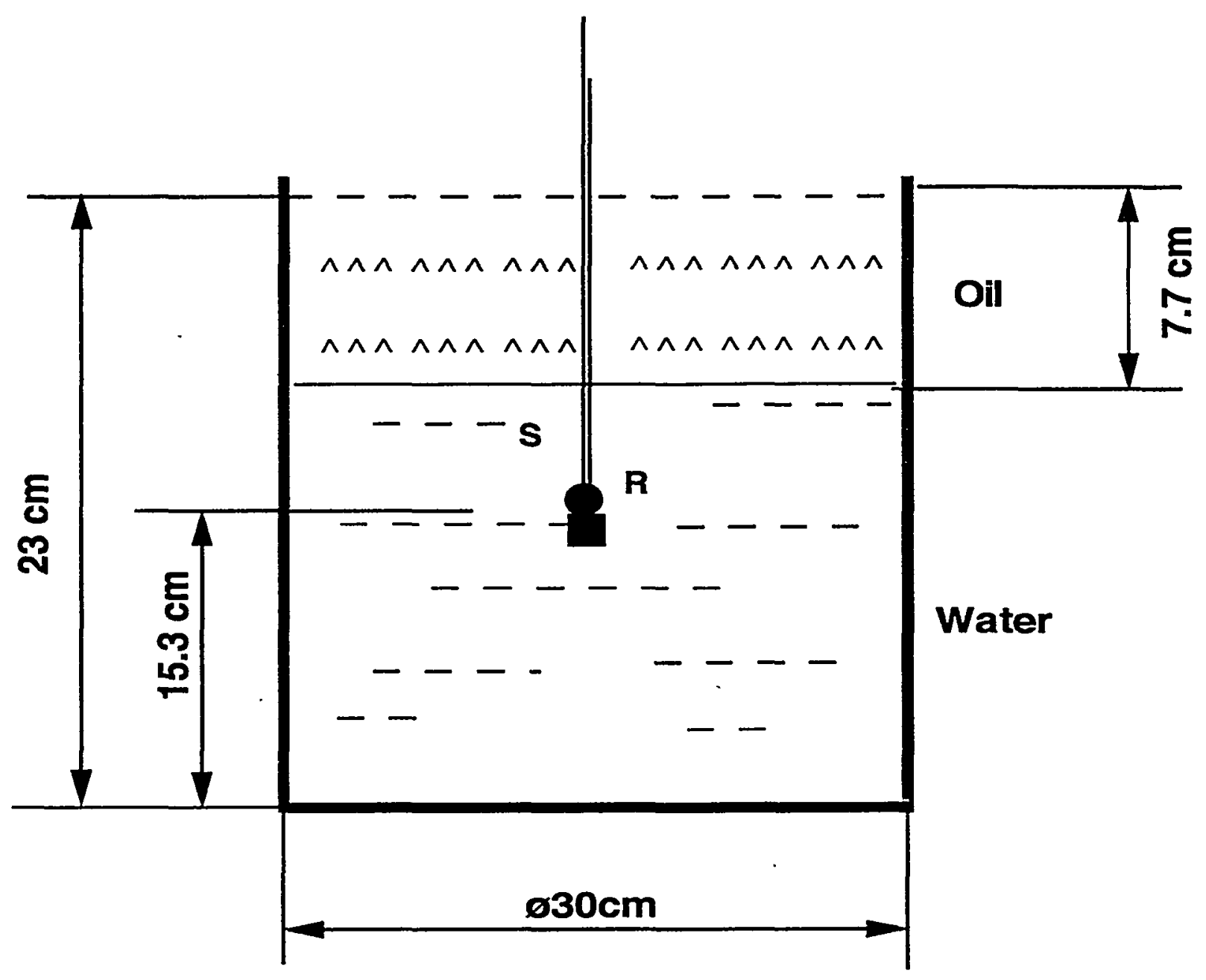

Figure 3: Diagram of the physical model arrangement simulating a Hanford tank. The pressure-sensitive receiver, $R$, and the source, $S$, were placed along the center line of the tank model. This setup was used to measure the resonance spectrum of the system. 


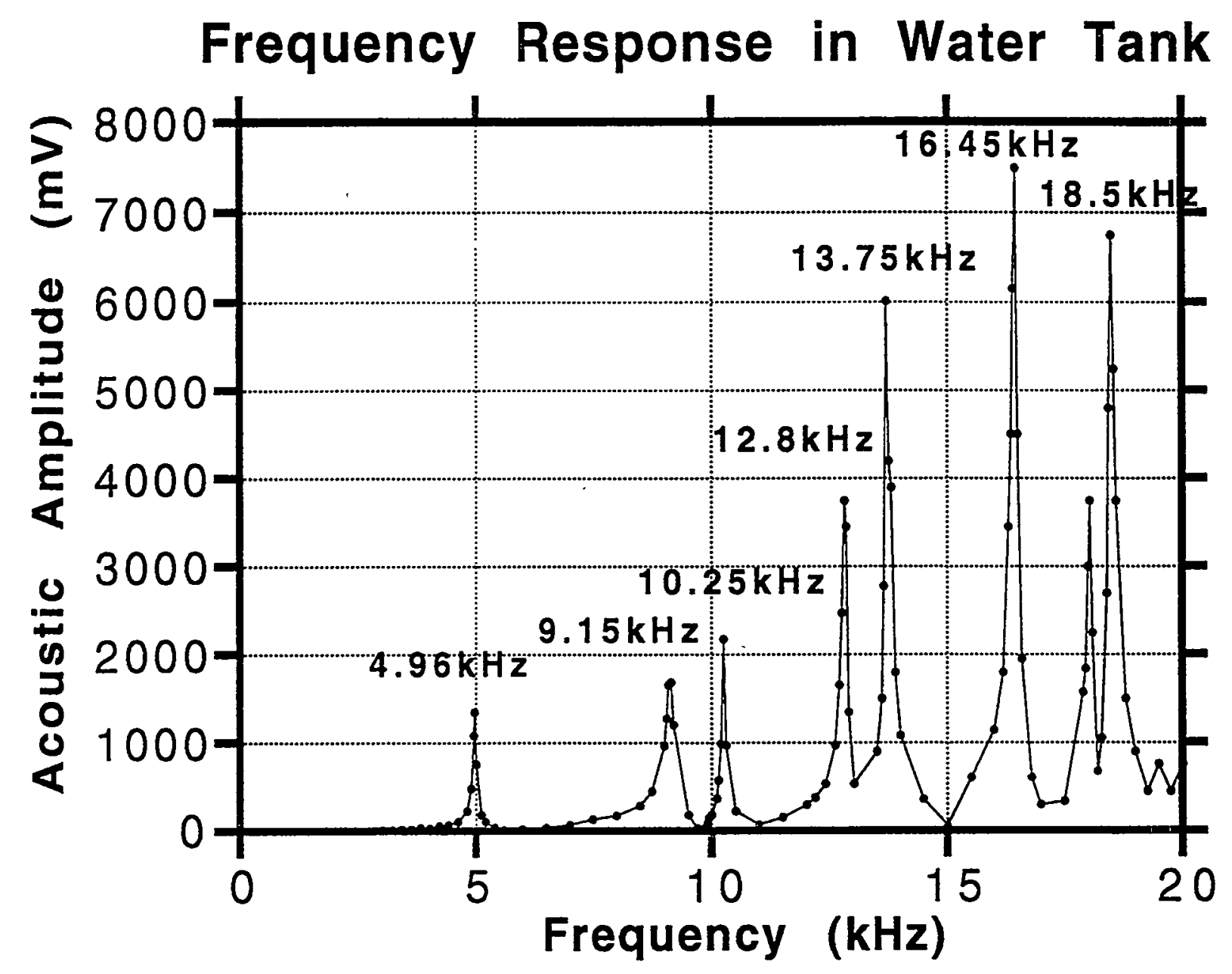

Figure 4: Resonance spectrum that was measured in the model tank filled with water. 


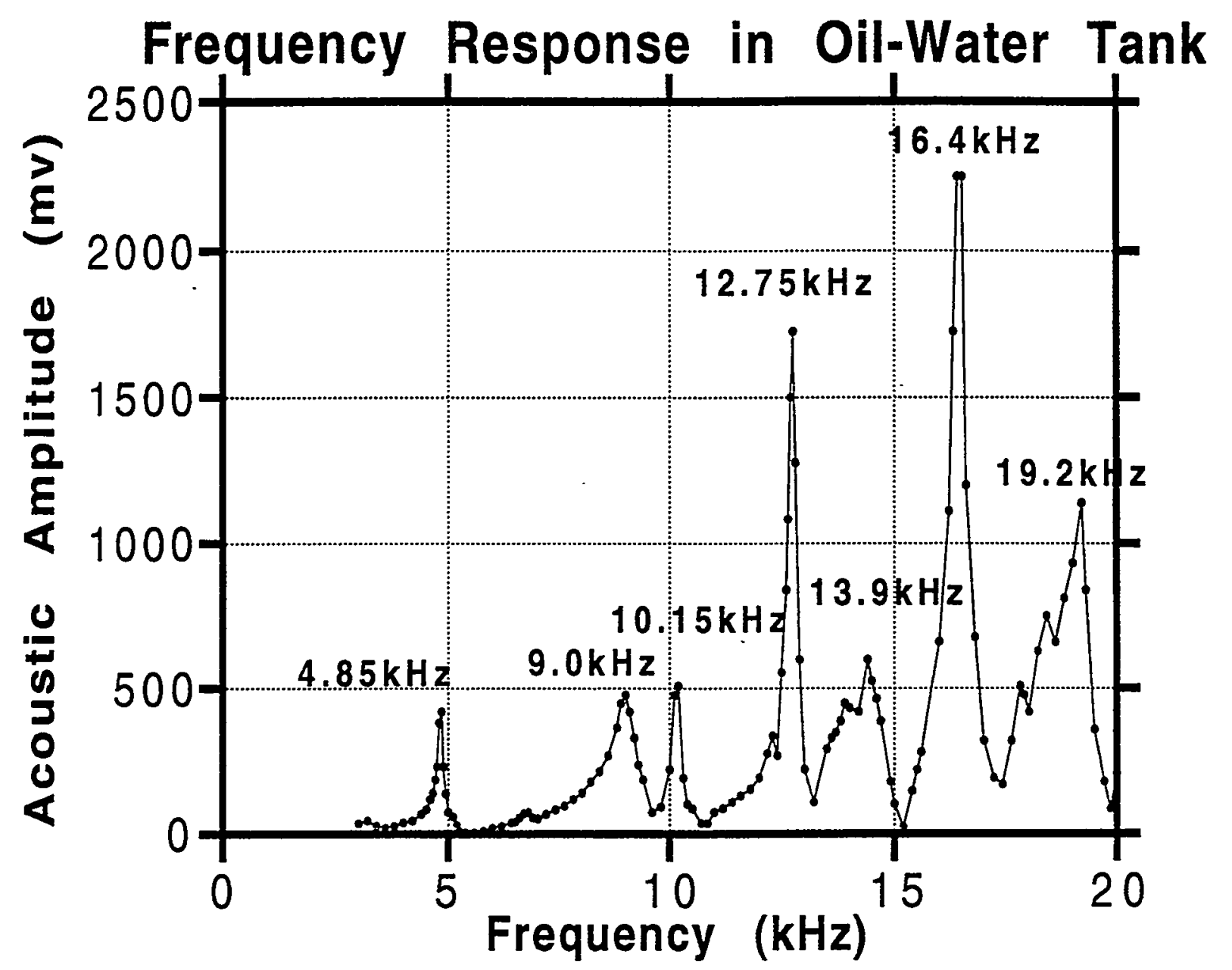

Figure 5: Resonance spectrum that was measured in the model tank filled with oil and water. 
harmonics shown in resonance spectrums, vibration distributions in both radial and axial directions are measured with experimental setups illustrated in Figures 6 and 7, respectively. We discuss our laboratory as well as theoretical results in the following two subsections.

\subsection{Measurements and Theoretical Computations for the Pure Water Tank}

Equation (6) needs adjustment so as to fit the free surface boundary condition at the tank bottom:

$$
k_{z l}=\frac{\pi l}{2 h}, \quad \text { with } l=0,1, \cdots
$$

Therefore, in contrast to the rigid boundary case, here mode $(m, l)$ denotes $m$ and $l$ antinodes in the radial and axial directions, respectively. Figures 8 and 9 display the measured vibration distribution (pressure field) for each of the harmonics in Figure 4. Harmonics at frequencies of $4.96 \mathrm{kHz}$ and $9.15 \mathrm{kHz}$ are, therefore, identified as mode $(1,1)$ and $(2,1)$. Here, mode $(m, l)$ indicates $m$ anti-nodes in the radial direction and $l$ anti-nodes in the axial direction.

Substituting equations (24) and (25) into equation (9), we build an expression that relates harmonic frequencies with the velocity of the water and tank geometries. For mode $(1,1)$ and $(2,1)$, harmonic frequencies are expressed as

$$
f_{1.1}=\frac{v_{f}}{2 \pi} \sqrt{\left[\frac{\operatorname{root}_{1}\left[J_{0}(x)\right]}{R}\right]^{2}+\left(\frac{\pi}{2 h}\right)^{2}}
$$

and

$$
f_{2.1}=\frac{\nu_{f}}{2 \pi} \sqrt{\left[\frac{\operatorname{root}_{2}\left[J_{0}(x)\right]}{R}\right]^{2}+\left(\frac{\pi}{2 h}\right)^{2}}
$$

where $f_{1,1}=4.96 \mathrm{kHz}$ and $f_{2.1}=9.15 \mathrm{kHz} ;$ root $_{1}\left[J_{0}(x)\right]$ and $\operatorname{root}_{2}\left[J_{0}(x)\right]$ are 2.4048 and 5.5201 , representing the first and second roots of the Bessel function of zero order, respectively. From equations (26) and (27), we estimated the velocity and height of the 


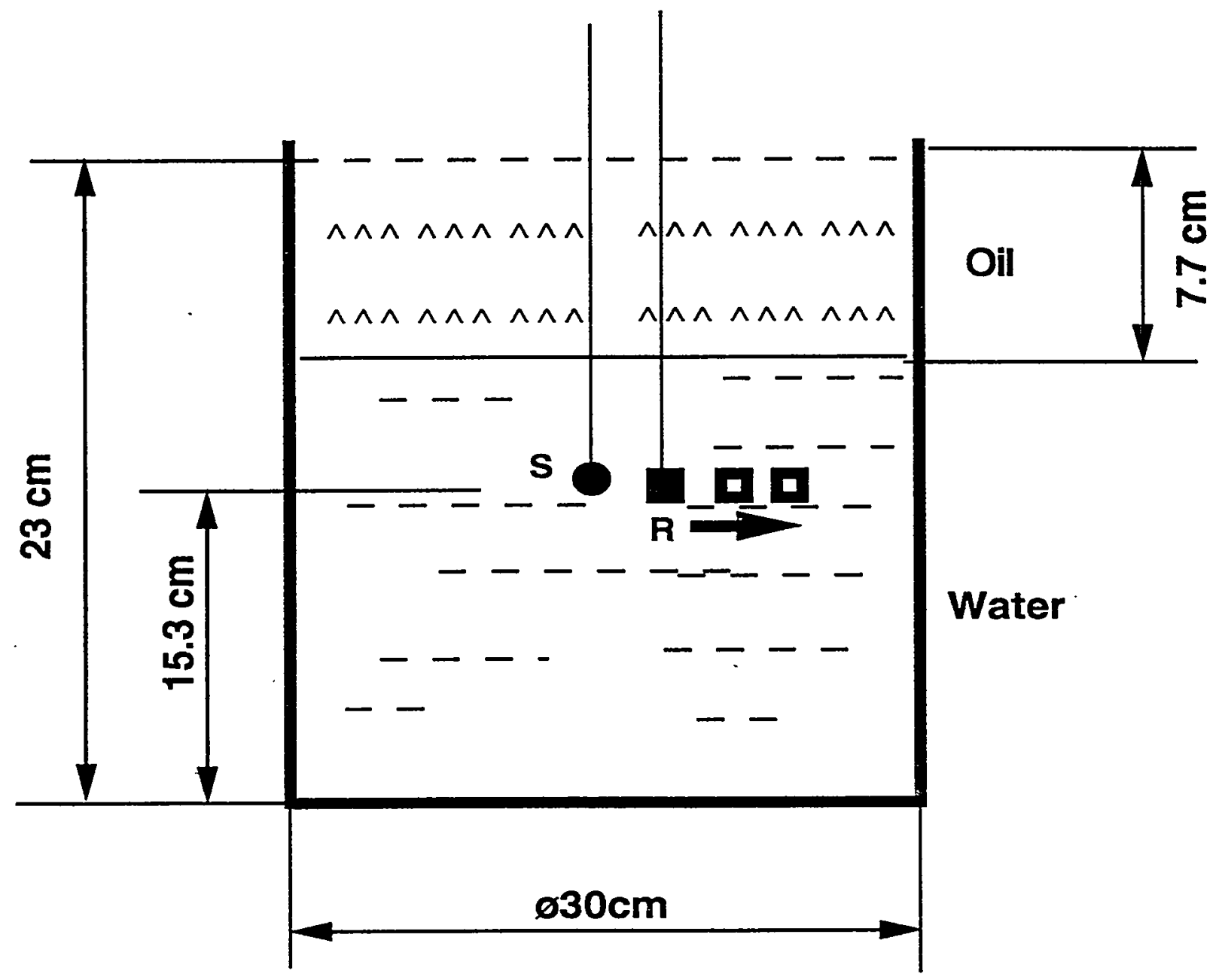

Figure 6: Diagram for measuring the acoustic field along the radial direction with a continuous sinusoidal signal generated by the source. 


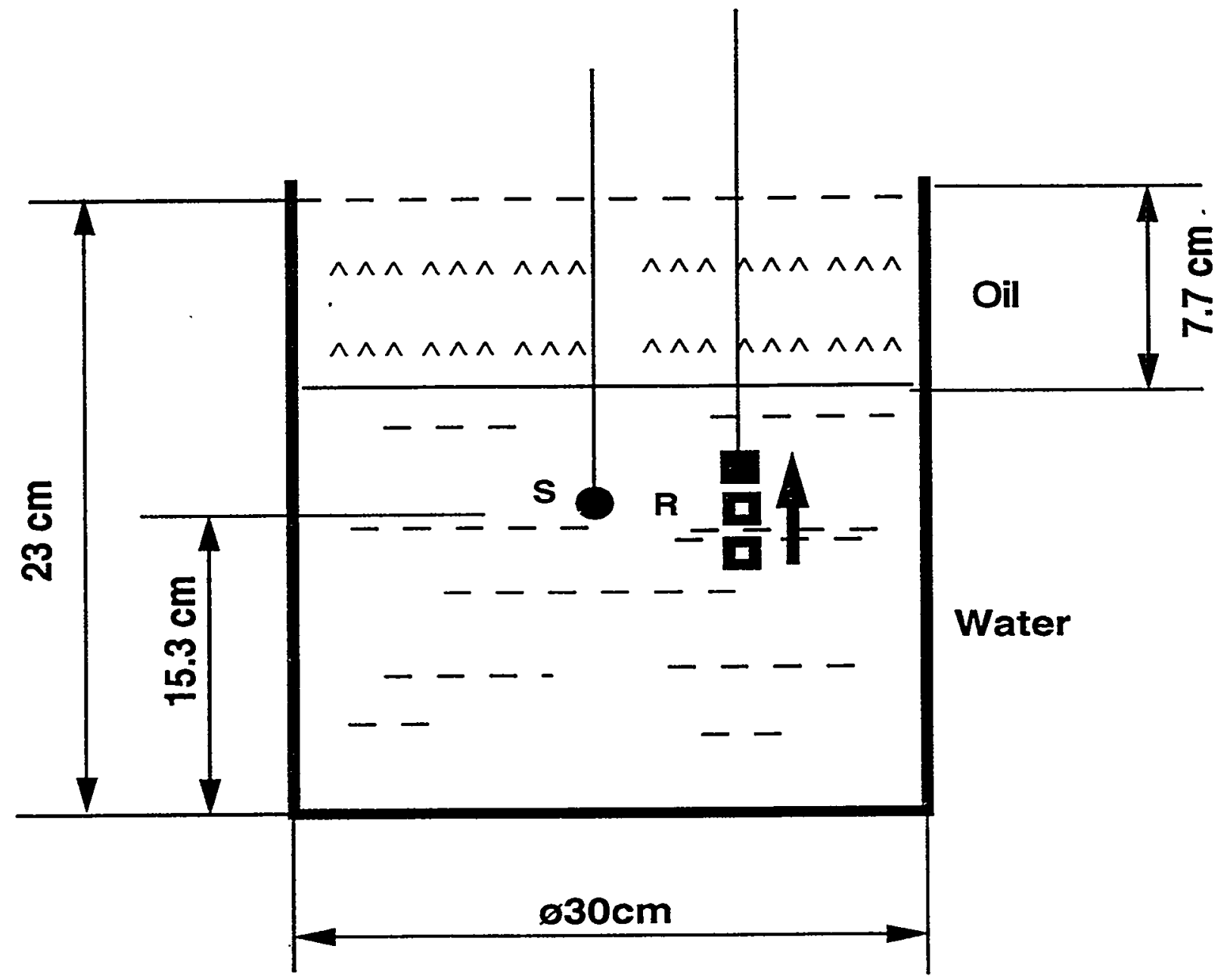

Figure 7: Diagram for measuring the acoustic field along the vertical direction with a continuous sinusoidal signal generated by the source. 


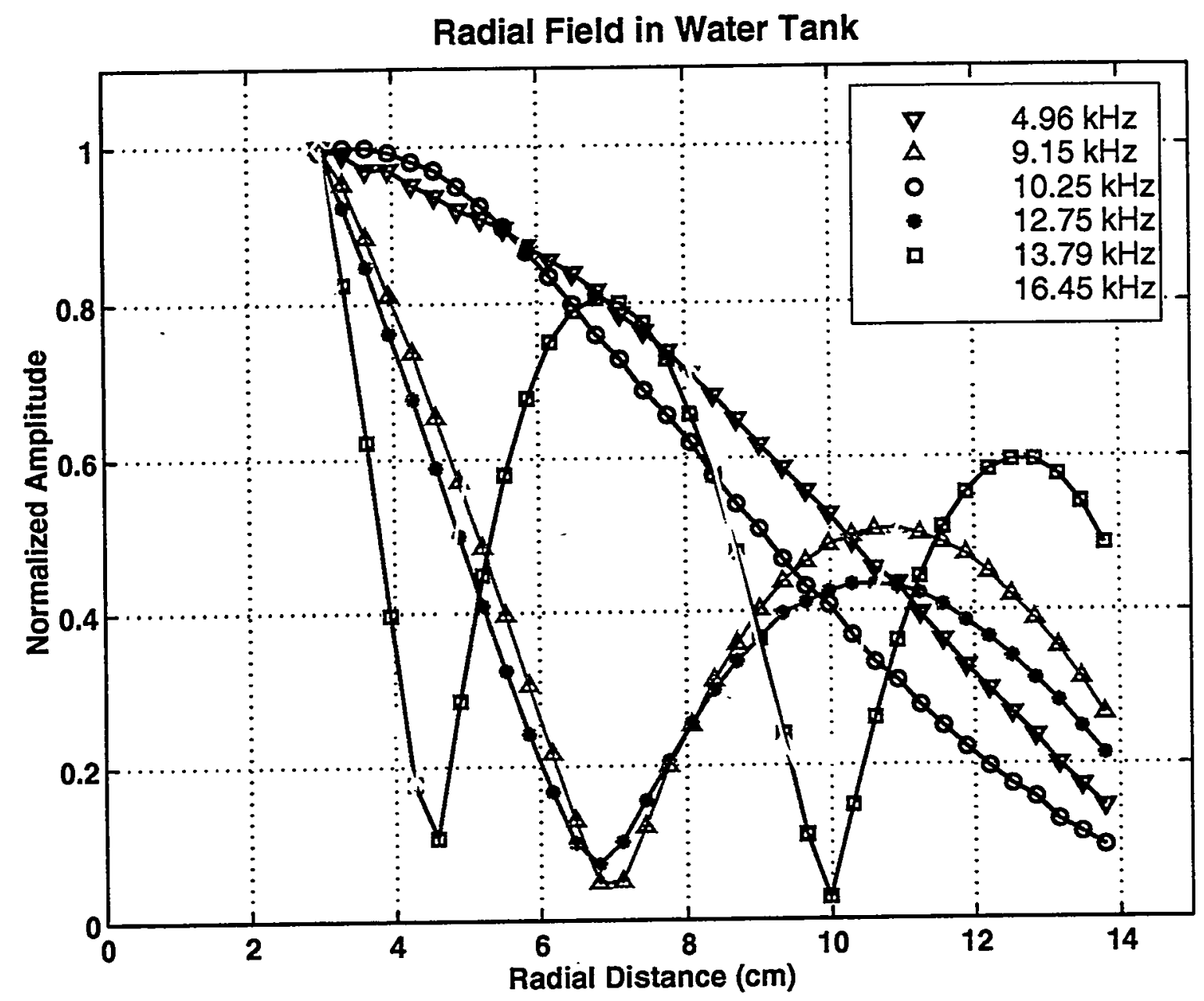

Figure 8: Measurements of pressure field distribution in the radial direction for harmonic modes that are measured in figure 4 in the water tank. 


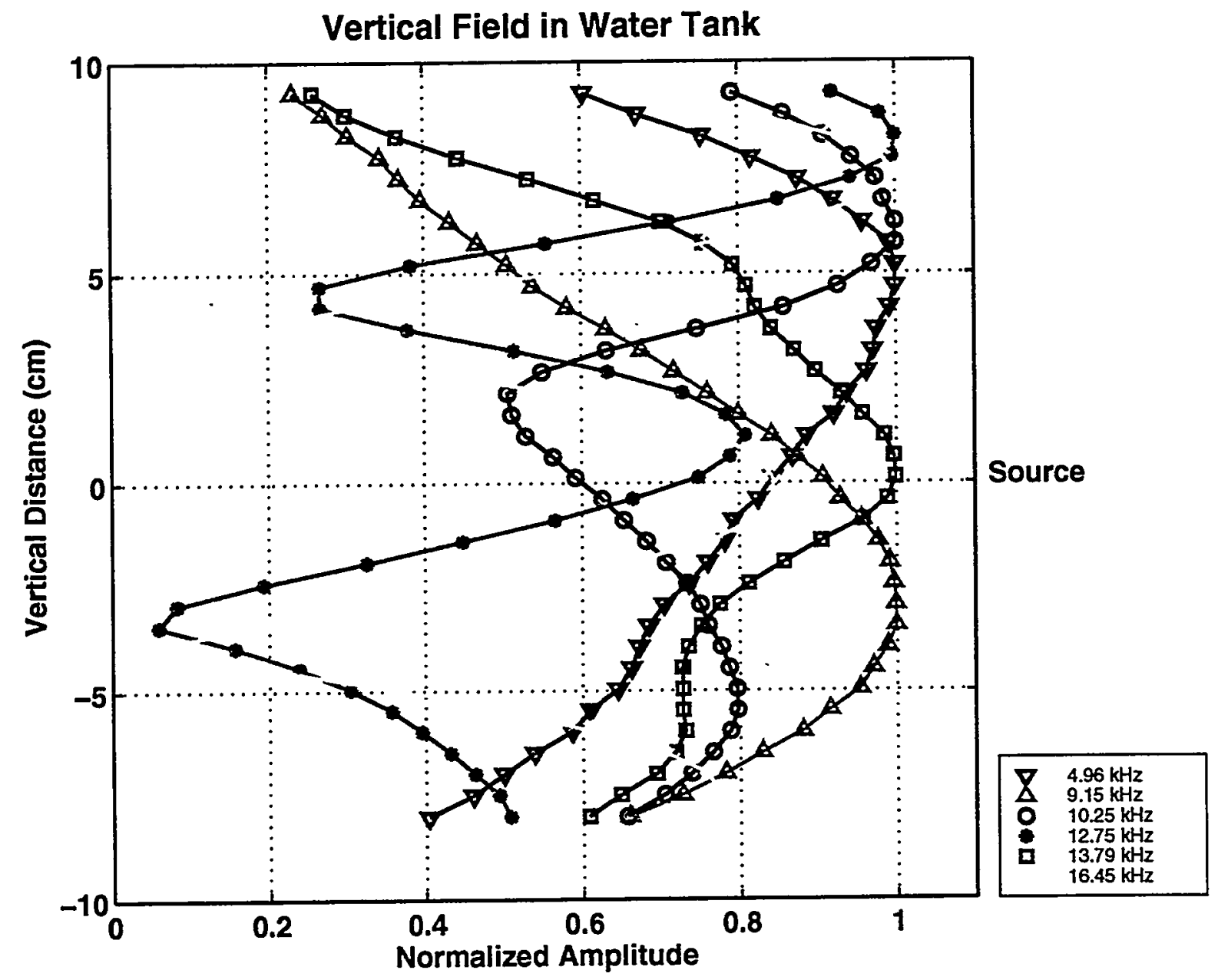

Figure 9: Measurements of pressure field distribution in the axial direction for harmonic modes that are measured in figure 4 in the water tank. 
water in our model tank. Estimations for fluid velocity and height are $1485.5 \mathrm{~m} / \mathrm{s}$ and 22.6 $\mathrm{cm}$, respectively, with errors smaller than $2 \%$ compared to their actual values: $1480 \mathrm{~m} / \mathrm{s}$ and $23 \mathrm{~cm}$.

Under free surface boundary conditions, a theoretical pressure field with normalized amplitude at position $(r, z)$ is described by the following formula:

$$
P(r, z)=J_{0}\left(k_{m}^{(0)} r\right) \sin \left(k_{z l} z\right) .
$$

Note that $\cos \left(k_{-1} z\right)$ drops out so as to fit free surface boundary conditions at the bottom of the pot and the surface of the fluid. Figures 10-15 show the measured vertical and radial pressure field together with the corresponding theoretical computation result for each of the harmonics measured in Figure 4. They agree with each other quite well. The theoretical computation for harmonic frequencies are listed below together with the experiment results.

\begin{tabular}{|l|c|c|c|}
\hline & Experiment $(\mathrm{kHz})$ & $\begin{array}{c}\text { Theory } \\
(\mathrm{kHz})\end{array}$ & $\begin{array}{c}\text { Measurement Error } \\
(\%)\end{array}$ \\
\hline Mode $(1,1)$ & 4.96 & 4.96 & 0 \\
\hline Mode $(2,1)$ & 9.15 & 9.15 & 0 \\
\hline Mode $(1,2)$ & 10.25 & 10.52 & 2.6 \\
\hline Mode $(2,3)$ & 12.78 & 13.03 & 1.2 \\
\hline Mode $(3,1)$ & 13.79 & 13.79 & 0 \\
\hline Mode $(3,3)$ & 16.45 & 16.62 & 1.0 \\
\hline
\end{tabular}

Theoretical results and experiment measurements match well for both harmonic frequencies and spatial distributions of each of the harmonic vibrations.

\subsection{Measurements and Theoretical Computations for the Oil-Water Tank}

Five harmonic frequencies, $4.85 \mathrm{kHz}, 9.00 \mathrm{kHz}, 10.15 \mathrm{kHz}, 12.75 \mathrm{kHz}$ and 16.40 $\mathrm{kHz}$, were observed below $17 \mathrm{kHz}$ in the model tank when filled with two layers of fluids: oil and water (Figure 5). Similarly, measurements of vibration distributions in the radial and axial directions were performed to identify the harmonic mode that each of the harmonic frequencies corresponds to. Sequentially from low to high in frequency, the five harmonic frequencies correspond to modes $(1,1),(2,1),(1,3),(2,3)$ and $(3,3)$. According 

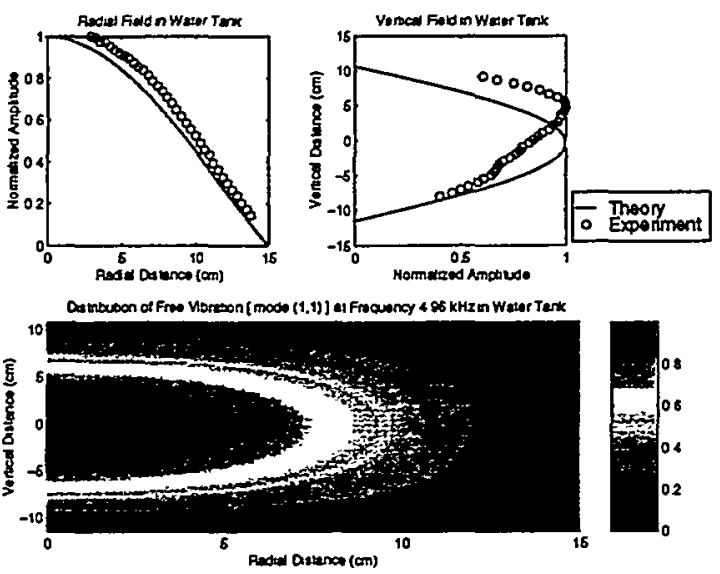

Figure 10: Experiment measurements and theoretical computation of radial and vertical pressure field distribution in a water tank at harmonic frequency: $4.96 \mathrm{kHz}$ (measured), 4.96 $\mathrm{kHz}$ (theory).
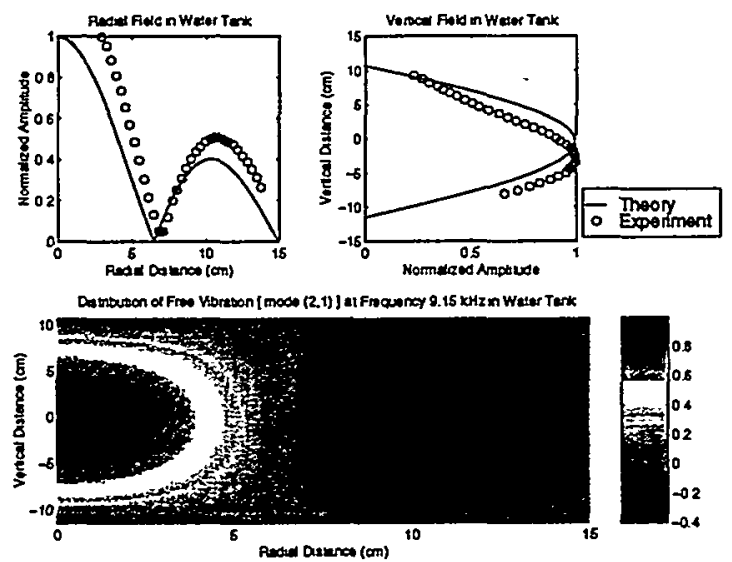

Figure 11: Experiment measurements and theoretical computation of radial and vertical pressure field distribution in a water tank at harmonic frequency: $9.15 \mathrm{kHz}$ (measured), 9.15 $\mathrm{kHz}$ (theory). 

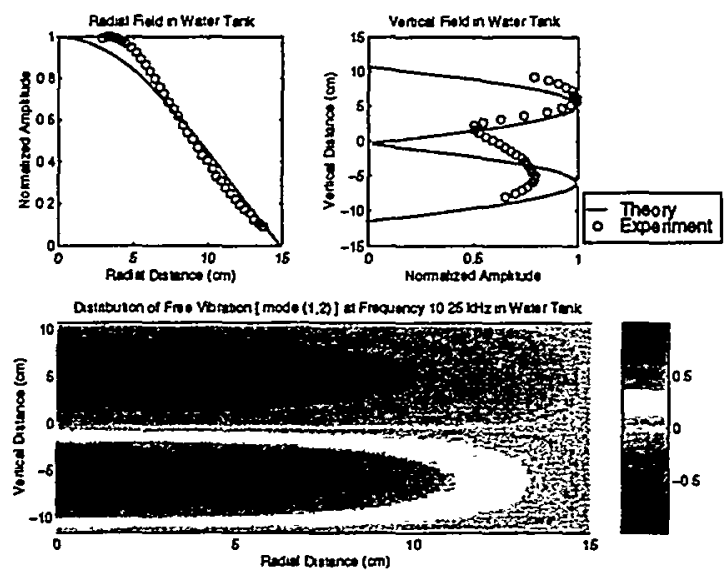

Figure 12: Experiment measurements and theoretical computation of radial and vertical pressure field distribution in a water tank at harmonic frequency: $10.25 \mathrm{kHz}$ (measured), $10.52 \mathrm{kHz}$ (theory).
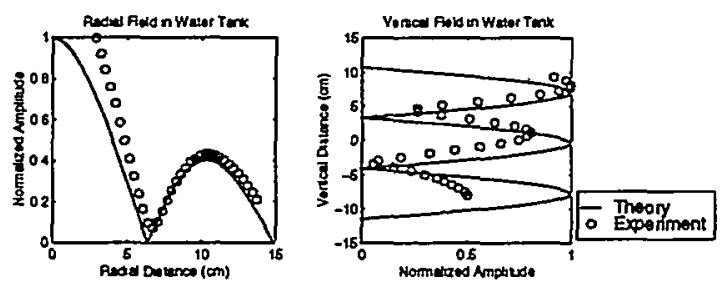

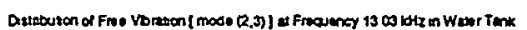

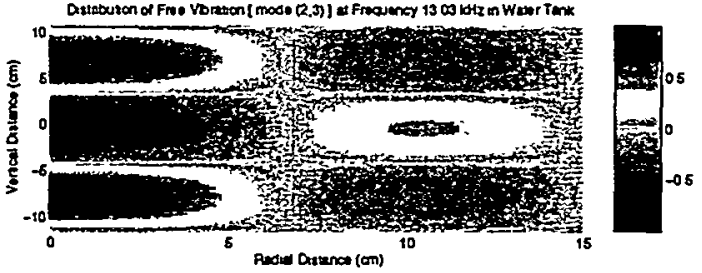

Figure 13: Experiment measurements and theoretical computation of radial and vertical pressure field distribution in a water tank at harmonic frequency: $12.78 \mathrm{kHz}$ (measured), $13.03 \mathrm{kHz}$ (theory). 

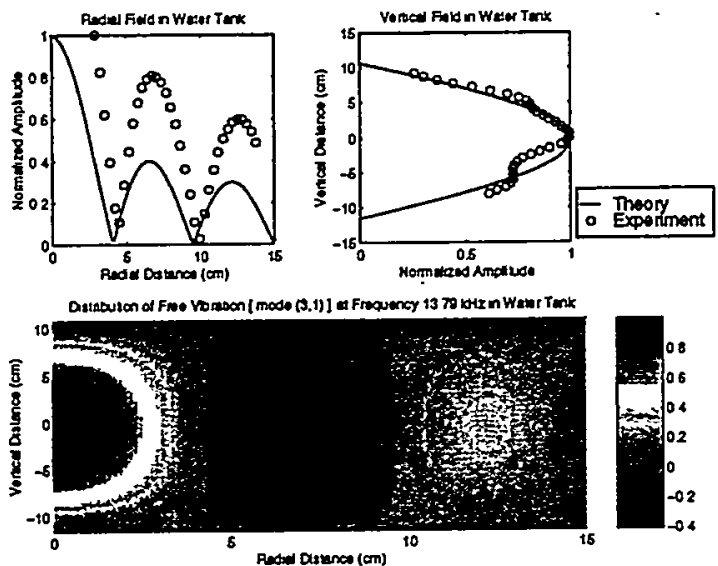

Figure 14: Experiment measurements and theoretical computation of radial and vertical pressure field distribution in a water tank at harmonic frequency: $13.79 \mathrm{kHz}$ (measured), $13.79 \mathrm{kHz}$ (theory).
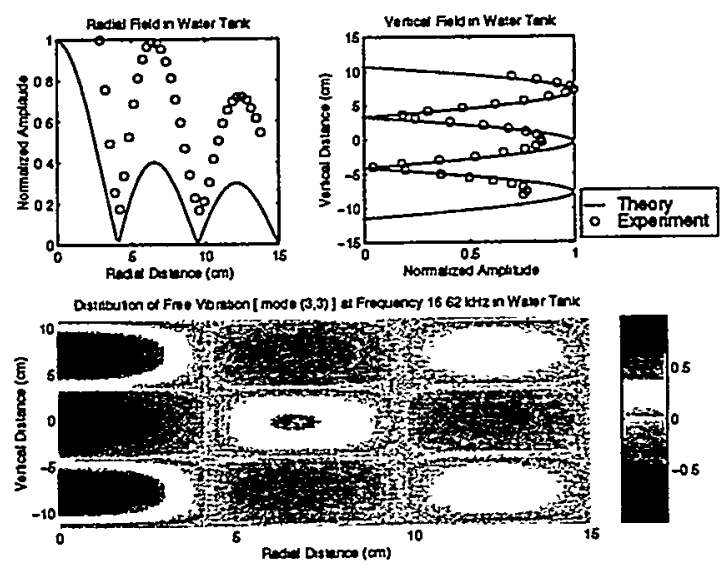

Figure 15: Experiment measurements and theoretical computation of radial and vertical pressure field distribution in a water tank at harmonic frequency: $16.45 \mathrm{kHz}$ (measured), $16.62 \mathrm{kHz}$ (theory). 
to the analysis in section 4 , we need at least 4 harmonics to resolve thicknesses of layers, densities and velocities of oil and water in our model tank. Before we can proceed to estimate these physical properties of the two layers of fluids, a small change is required in equation (19) so as to fit the free surface boundary condition at the bottom of our model tank. The boundary conditions in equation (15)

should be $\left.P_{\mathrm{I}}\right|_{z=0}=0$ rather than $\left.u_{z}^{(1)}\right|_{z=0}=0$, while others remain the same under the condition of free surface boundary. Consequently, in our two-layer case $(N=2)$, equation (19) becomes

$\mathrm{C}=\left[\begin{array}{llll}c_{11} & & & \\ c_{21} & c_{22} & c_{23} & c_{24} \\ c_{31} & c_{32} & c_{33} & c_{34} \\ & & c_{43} & c_{44}\end{array}\right]$

where the non-zero elements can be computed with formulas in the Appendix. All other equations in section 4 remain the same. Using

axial direction, $k_{z l}^{(1)}$ and $k_{z l}^{(2)}$ are calculated so as to compute harmonic equations (23) and (22), eigenvalues in the

axial direction, $k_{z l}^{(1)}$ and $k_{z l}^{(2)}$ are calculated so as to compute harmonic

frequencies, $f_{1,1}, f_{2,1}, f_{1,2}, f_{2.3}$, and $f_{3,3}$, from equations (9) and (24). Thicknesses of both layers, and velocities and densities of both fluids in the model tank are estimated using a simple iterative random searching method. The estimated results are listed along with the actual values below: 


\begin{tabular}{|l|r|r|r|}
\hline & \multicolumn{1}{|c|}{ Estimated Value } & \multicolumn{1}{|c|}{ Actual Value } & Estimation Error (\%) \\
\hline $\begin{array}{l}\text { Thickness of Water } \\
\text { Layer }(\mathrm{cm})\end{array}$ & 15.1 & 15.3 & 1.3 \\
\hline $\begin{array}{l}\text { Thickness of Oil } \\
\text { Layer }(\mathrm{cm})\end{array}$ & 7.5 & 7.7 & 2.6 \\
\hline $\begin{array}{l}\text { Density of Water } \\
\text { (g/cm) }\end{array}$ & 1.0 & 1.0 & 0 \\
\hline $\begin{array}{l}\text { Density of Oil } \\
\text { (g/cm) }\end{array}$ & 0.84 & 0.84 & 0.4 \\
\hline $\begin{array}{l}\text { Velocity of Water } \\
\text { (m/s) }\end{array}$ & 1485.5 & 1480 & 0.3 \\
\hline Velocity of Oil $(\mathrm{m} / \mathrm{s})$ & 1385 & 1381 & \\
\hline
\end{tabular}

Estimations agree with the actual values quite well. The errors are believed to come from measurements and the random searching algorithm. Harmonic frequencies are listed below for both experiments and theoretical computation:

\begin{tabular}{|l|c|c|c|}
\hline & Experiment $(\mathrm{kHz})$ & Theory $(\mathrm{kHz})$ & Error (\%) \\
\hline Mode $(1,1)$ & 4.85 & 4.93 & 1.6 \\
\hline Mode $(2,1)$ & 9.00 & 9.10 & 1.1 \\
\hline Mode $(1,3)$ & 10.15 & 10.17 & 0.2 \\
\hline Mode $(2,3)$ & 12.75 & 12.74 & 0 \\
\hline Mode $(3,3)$ & 16.40 & 16.38 & 0 \\
\hline
\end{tabular}

From equation (18), we obtain

$$
\begin{aligned}
& A_{m}^{(1)}=0, \\
& B_{m}^{(1)}=\left(\frac{C_{33} C_{44}}{C_{32} C_{43}}-\frac{C_{34}}{C_{32}}\right) B_{m}^{(2)} \\
& \text { and } \\
& A_{m}^{(1)}=-\frac{C_{44}}{C_{43}} B_{m}^{(2)} .
\end{aligned}
$$

Therefore, the normalized pressure field at $(r, z)$ for each vibration mode $(m, l)$ can be represented as 
$P_{1}=J_{0}\left(k_{r m}^{(0)} r\right) \sin \left(k_{z l}^{(1)} z\right) \quad$ for $0 \leq z \leq h_{1}\left(h_{1}=15.3 \mathrm{~cm}\right)$

and

$\mathrm{P}_{2}=\frac{\rho_{\mathrm{f}}^{(2)}}{\rho_{\mathrm{f}}^{(1)}} \frac{\mathrm{c}_{32} \sqrt{\mathrm{c}_{43}^{2}+\mathrm{c}_{44}^{2}}}{\mathrm{C}_{33} \mathrm{c}_{44}-\mathrm{c}_{34} \mathrm{C}_{43}} \mathrm{~J}_{0}\left(\mathrm{k}_{\mathrm{m}}^{(0)} r\right) \sin \left(k_{z l}^{(2)} z-\phi_{0}\right)$ for $h_{1} \leq z \leq h(h=23 \mathrm{~cm})$

where $\phi_{0}=\tan ^{-1}\left(\frac{\mathcal{C}_{44}}{C_{43}}\right)$, representing the phase shift of $\sin \left(k_{z l}^{(2)} z\right)$

that makes $P_{2}$ fit the free surface boundary condition at $z=h$. The measured resonance spectrum is displayed in Figure 5. Figures 16-20 show the measured vertical and radial pressure field together with corresponding theoretical computation results for each of the harmonics measured in Figure 5. It is clear that theoretical results and experiment measurements match well for both resonance frequencies as well as spatial distribution of vibrations for each harmonic mode.

\section{Conclusions}

A theoretical framework for characterizing free vibrations of a tank partially filled with layers of inviscid and compressible fluids is developed and proved by an ultrasonic scale model experiment. Both theoretical results and experiment measurements show that the tank-fluids system resonates to an acoustic source at certain discrete frequencies because the tank-fluids system is of finite size. Estimations of fluid properties using experiment data and the theoretical model developed in this paper exhibits a close match with actual values. Each of the Hanford tanks has a roof with several risers that penetrate the roof and provide access to the interior. Resonance spectrums as well as vertical distributions of the pressure field can be measured from the risers, but not the radial distributions of the pressure field. Thus, besides physical properties of the wastes, mode order in the radial direction, $m$, also becomes one of the free parameters than are to be determined in the inversion processing. As long as the number of layers inside the tank is not so large that differences between neighboring resonance frequencies are smaller than 

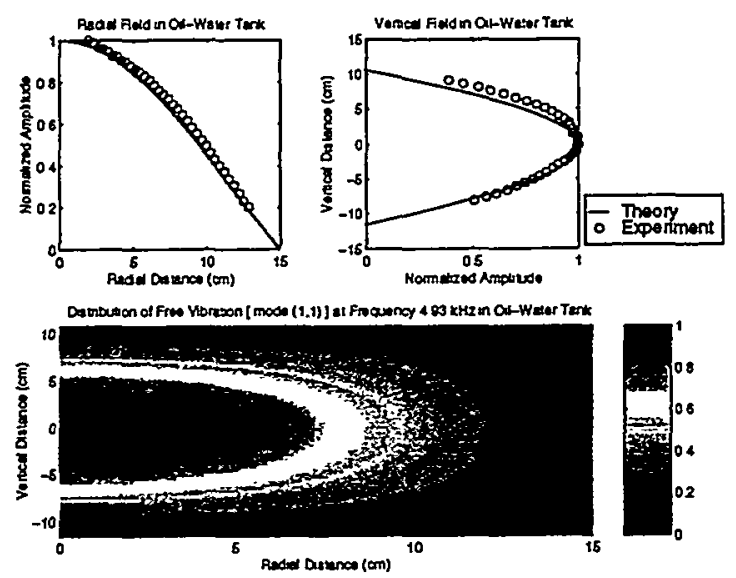

Figure 16: Experiment measurements and theoretical computation of radial and vertical pressure field distribution in an oil-water tank at harmonic frequency: $4.85 \mathrm{kHz}$ (measured), $4.93 \mathrm{kHz}$ (theory).
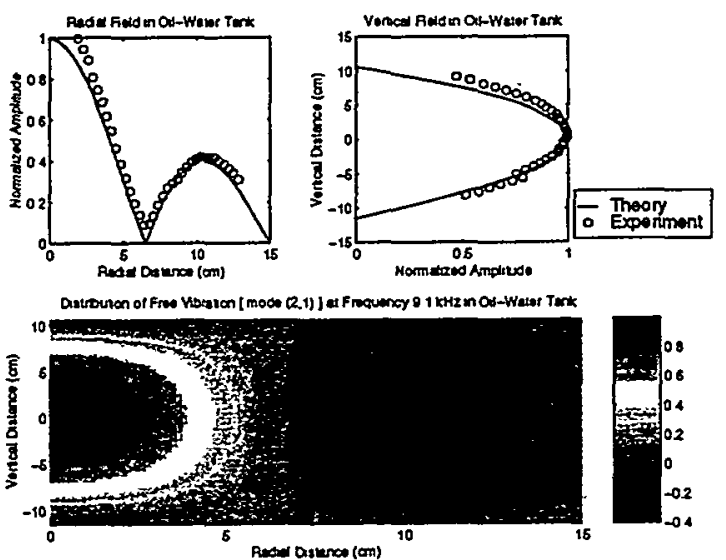

Figure 17: Experiment measurements and theoretical computation of radial and vertical pressure field distribution in an oil-water tank at harmonic frequency: $9.00 \mathrm{kHz}$ (measured), $9.10 \mathrm{kHz}$ (theory). 

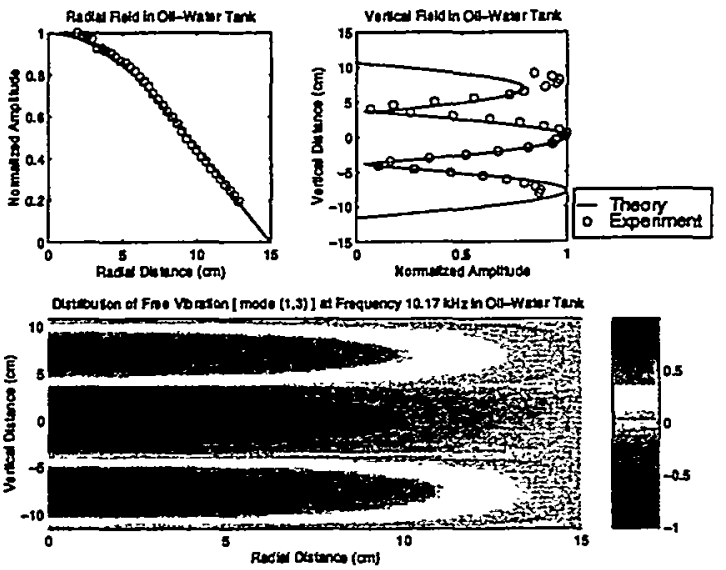

Figure 18: Experiment measurements and theoretical computation of radial and vertical pressure field distribution in an oil-water tank at harmonic frequency: $10.15 \mathrm{kHz}$ (measured), $10.17 \mathrm{kHz}$ (theory).
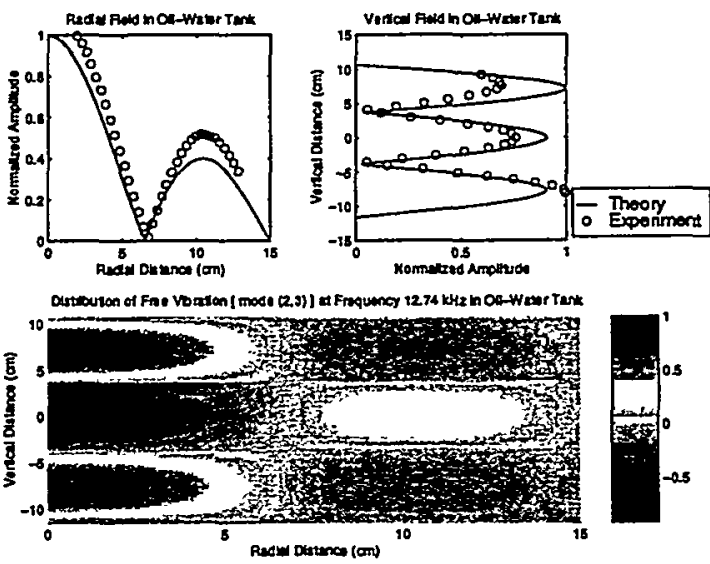

Figure 19: Experiment measurements and theoretical computation of radial and vertical pressure field distribution in an oil-water tank at harmonic frequency: $12.75 \mathrm{kHz}$ (measured), $12.74 \mathrm{kHz}$ (theory). 

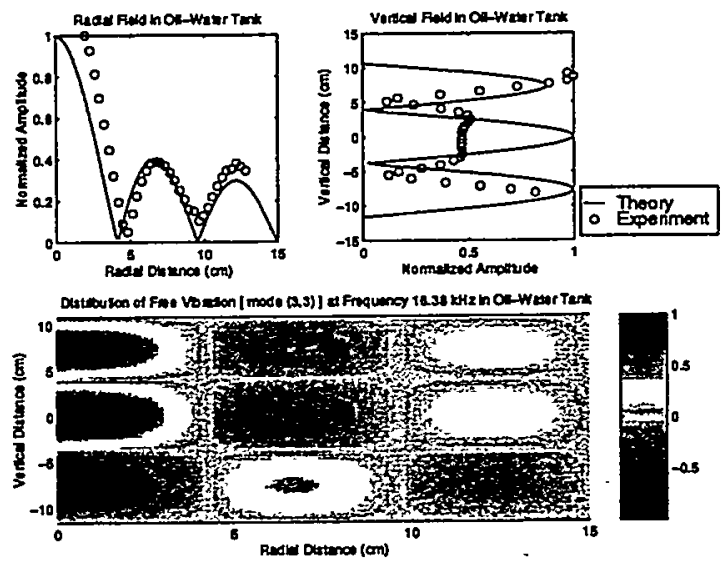

Figure 20: Experiment measurements and theoretical computation of radial and vertical pressure field distribution in an oil-water tank at harmonic frequency: $16.40 \mathrm{kHz}$ (measured), $16.38 \mathrm{kHz}$ (theory). 
measurement errors, physical properties of the wastes can be characterized reasonably well using the harmonic method of this paper.

\section{RELEVANCE, IMPACT, AND TECHNOLOGY TRANSFER}

This research project produced knowledge that can be used to make rapid estimates of the nature of wastes in underground tanks. These estimates can be made using small seismic sources and receivers on the earth's surface outside the tank. This knowledge is valuable if an early selection must be made between various kinds of sampling, pumping, sluicing, etc. hardware. If such hardware performs properly no matter the nature of the waste, then even an estimate of the nature of the waste is not needed.

This project was a perfect example of the application of an old fundamental technique that has been used in many engineering and scientific fields, to a new, important, and specific problem. The earth sciences has used normal mode studies for decades to estimate the properties of the earth as a whole. Here, it was scaled down to a single underground tank application.

At this date it appears that this knowledge is not needed and will not be used. The hardware to be used to sluice and pump the wastes from Hanford tanks is robust enough that one does not need to know the nature of the wastes before operations begin. Therefore, there will be no impact on individuals, laboratories, departments, and institutions related to those tanks.

The project has created expertise with respect to the diagnostic capabilities of natural vibrations of large underground storage tanks. It was also determined that existing field hardware was imminently qualified for the task and no new seismic sources or recording systems are needed.

The investigators have increased their computational skills and their ability to make important new models in the physical modeling laboratory. In addition, the research has increased our knowledge of the appropriate theory and algorithms necessary to numerically 
model the normal modes of large underground tanks. It has also increased our skills in the physical modeling laboratory. This technology could be field tested immediately if the need arose.

No other government agencies or private enterprises have expressed interest in this technology. However, we have not advertised the fact that we possess this new information.

\section{PROJECT PRODUCTIVITY}

The project accomplished all of its goals.

\section{PERSONNEL SUPPORTED}

This project supported one faculty member (M. N. Toksöz), three research staff (R. Rao, R. Turpening, Z. Zhu), and one graduate student (X. Huang).

\section{PUBLICATIONS}

No publications resulted directly from this work.

\section{INTERACTIONS}

This research was presented at the Environmental Management Science Program Workshop in Chicago on July 27-30, 1998.

\section{TRANSITIONS}

Our expertise in numerical modeling and small-scale physical modeling has been used in many other areas of research. The specific information generated here about underground tanks has not moved into other areas. 


\section{PATENTS}

We have not applied for patents in this area of underground tank technology.

\section{FUTURE WORK}

A need for the rapid estimation of the nature of the contents of underground tanks will probably arise in the future. In anticipation of that need, we should at least pursue the following lines of investigation.

- Perform a field investigation of the modes of a waste-filled tank (known contents) given receivers in a LOW and simultaneously on the earth's surface while seismic source(s) are on the surface. Success on the surface would extend the usefulness of the technique.

- Complete line of investigation (numerical, small physical models, full-scale field studies) with receivers on the surface and source(s) on the surface.

- Complete line of investigation for the case of one or more layers of a gas beneath the waste layers in a tank.

\section{LITERATURE CITED}

Butkov, E., 1968, Mathematical Physics, Addison-Wesley Pub. Co., Reading, Mass.

Gilbert, F. and A. Dziewonski, 1975, An application of normal mode theory to the retrieval of structural parameters and source mechanisms from seismic spectra, Philosophical Trans. of Roy. Soc. London, A287, 187-269.

Migliori, A., J. Sarrao, and W. Visscher, 1993, Resonant ultrasound spectroscopic techniques for measurement of the elastic-moduli of solids, Physica B, 183, 1-24.

Mochizuki, E., 1986, The free oscillations of an anisotropic and heterogeneous earth, Geophys. J. Roy. Astron. Soc., 86, 167.

Turpening, R., Z. Zhu, C. Caravana, J. Matarese, and W. Turpening, 1995, Acoustic imaging of underground storage tank wastes-A feasibility study, Technical Report, Westinghouse Hanford Co. and MIT, for the U.S. Dept. of Energy. 


\section{APPENDIX}

Listed below are non-zero elements in $C$ of equations (19), (18), and (29). They are functions of axial wavenumbers, fluid densities and velocities. For $j=1,2,3, \ldots, n-1$,

$$
\begin{array}{ll}
c_{12}=1 & \\
c_{2 j 2 j-1}=\cos \left(k_{z l}^{(j)} h_{j}\right), & c_{2 j+12 j-1}=\sin \left(k_{z l}^{(j)} h_{j}\right), \\
c_{2 j 2 j}=\sin \left(k_{z l}^{(j)} h_{j}\right), & c_{2 j+12 j}=-\cos \left(k_{z l}^{(j)} h_{j}\right), \\
c_{2 j 2 j+1}=-\frac{\rho_{f}^{(j+1)}}{\rho_{f}^{(j)}} \cos \left(k_{: l}^{(j+1)} h_{l}\right), & c_{2 j+12 j+1}=-\frac{k_{z l}^{(j+1)}}{k_{z l}^{(j)}} \sin \left(k_{z l}^{(j+1)} h_{j}\right), \\
c_{2 j 2 j+2}=-\frac{\rho_{t}^{(j+1)}}{\rho_{f}^{(j)}} \sin \left(k_{z l}^{(1+1)} h_{l}\right) \text { and } c_{2 j+1}{ }_{2 j+2}=\frac{k_{z l}^{(j+1)}}{k_{z l}^{(j)}} \cos \left(k_{z l}^{(j+1)} h_{j}\right) .
\end{array}
$$

When $j=N$,

$$
C_{2 N 2 N-1}=\cos \left(k_{z l}^{(N)} h\right) \text { and } \quad C_{2 N 2 N}=\sin \left(k_{z l}^{(N)} h\right) .
$$

